\title{
Science Academies Refresher Course on Crustal Strength Rheology and Seismicity (CSRS-2017)
}

\author{
15-26 May 2017 \\ at Indian Institute of Technology (Indian School of Mines) \\ Dhanbad 826004, Jharkhand \\ www.iitism.ac.in \\ Sponsored by Indian Academy of Sciences, Bengaluru \\ Indian National Science Academy, New Delhi \\ The National Academy of Sciences, India, Allahabad
}

\begin{abstract}
Science Academies Refresher Course is being organized in Indian Institute of Technology (Indian School of Mines), Dhanbad. This course will be an added source of inspiration to the faculty members, research scholars, and undergraduate/postgraduate students in particular and teaching fraternity in general. We hope that the refresher course taken by Geologists, Geophysicists, Mathematicians deeply interested in teaching and research, will motivate young minds and inspire faculty members to engage themselves in active teaching and research. The key features of this Course are enlisted as follows: Rheological behavior of rocks Variation of rheological properties inside the earth Effect of rheological properties on seismicity Study material will be provided to all participants in the form of soft and/or hard copy. Only 25 outstations and 10 Local Teachers/Research Scholars/Post graduate students will get an opportunity to participate in this course. Applications are invited from teachers with experience in teaching undergraduate and postgraduate courses in Geology, Geophysics, Earth Sciences, Mathematics and Physics. Maximum 35 applications will be considered and teachers who wish to participate in the Refresher Course may apply through proper channel with the following details: name, date of birth, gender, e-mail, official and residential addresses, telephone numbers, academic qualifications, courses taught, affiliation, positions held and tenure. It is also essential to submit a brief statement (between 250 and 500 words) as to why they think the Course will help to improve their classroom teaching of Geology/ Geophysics/Earth Science/Mathematics etc.
\end{abstract}

Applications should be submitted ONLINE by clicking the following link :

http://web-japps.ias.ac.in: 8080/Refreshcourse/RCSTST . jsp

A print copy of the application must also be sent by speed post forwarded by the Head of the Department/Center/Institute. It should reach the Course Coordinator before 15 April 2017. Outstation candidates will be provided local hospitality and round trip bus/train (three-tier AC) fare by the shortest route.Alternatively applications may be sent with necessary personal details by email (drmks29@ rediffmail.com). Please note that selected outstation participants will be paid III A/c fare by the shortest route with local hospitality. The applications should be forwarded through the Head of the Department/Center/Institute. The details you may also find on IIT(ISM) website: www.iitism.ac.in

Course Director: Prof. Alok K Gupta, F.N.A., F.N.Sc., F.N.A.Sc., National Center of Experimental Mineralogy \& Petrology, University of Allahabad, Allahabad-211002

Course Coordinators: Dr. M. K. Singh and Prof. S Mohanty, Indian Institute of Technology (Indian School of Mines), Dhanbad - 826 004, Jharkhand, Email: drmks29@rediffmail.com

Selected participants will be intimated through email by 30th April, 2017.

Last date for receiving applications 15 April, 2017. 